\title{
Subversões do lírico no contexto prisional feminino de Sergipe
} Maria Aparecida Silva Ribeiro ${ }^{1}$

Este artigo comenta a empreitada político-estética do grupo Penarte, em apoio ao Projeto Florescer Construindo a Liberdade, do Ministério Público, em parceria com a Secretaria de Estado da Justiça de Sergipe, junto às internas do Presídio Feminino de Sergipe (Prefem). Constata-se o avanço da proposta de extensão acadêmica - o projeto Letras do Cárcere: Práticas de Leitura e Escrita no Contexto Prisional Feminino do Estado de Sergipe, vinculado à licenciatura em língua portuguesa e ao Programa de Pós-Graduação em Letras, da Universidade Federal de Sergipe (UFS) -, para além dos 12 meses de execução (2012-2013) e dos objetivos inicialmente propostos. Apresentam-se nesse texto as bases para uma incursão nos domínios da pesquisa científico-metodológica sobre educação social, a partir do exame e fomento de um conjunto de práticas extraescolares de leitura e escrita à luz do conceito de "regime de práticas discursivas" (Foucault).

Usualmente, portadoras de extrema dificuldade de organizar suas "vivências" e compartilhá-las enquanto "experiência", as mulheres que tomam parte na escrita do livro intitulado Outras vozes: poemas e relatos das presidiárias (Sergipe, 2012) exercitaram práticas de "rememoração" e "reminiscência criadora" naquela situação específica de criação. $\mathrm{O}$ uso da terminologia benjaminiana, nesse caso, alude à consideração dos modos com que o filósofo da modernidade situa o papel da memória nos discursos de (re)construção do passado, em sua coletânea de escritos da década de 1930:

A língua tem indicado inequivocamente que a memória não é um instrumento de exploração do passado; é, antes, o meio. É o meio onde se deu a vivência, assim como o solo é o meio no qual as antigas cidades estão soterradas. Quem pretende se aproximar do próprio passado soterrado deve agir como um homem que escava (Benjamin, 1997, p. 239)

Os textos, formatados em relatos, poemas, cartas - majoritariamente enunciados em primeira pessoa -, transformam em projeções imagéticas

\footnotetext{
${ }^{1}$ Doutora em letras e professora da Universidade Federal do Estado do Rio de Janeiro (Unirio), Rio de Janeiro, RJ, Brasil. E-mail: masribeiro97@ gmail.com
} 
o conteúdo de lembranças, os fragmentos de um passado revisitado por um olhar investigativo - "arqueológico", no dizer de Benjamin -, visando alcançar estratos cada vez mais fundos da memória.

Durante os seis meses de duração do Penarte, a participação regular em atividades artístico-pedagógicas promoveu entre as internas uma tendência reminiscente, quase prolixa, voltada para a escrita dos termos da própria vida pregressa. O reencontro com o passado revelou um "ser" (ainda na terminologia benjaminiana) extremamente modificado pelas condições adversas do presente. Erigido nas representações do lírico, o sujeito enunciado nos textos das internas tem suas vivências acrescidas de relações causais, de reverberações e impactos que se vão inferindo à medida que a escrita procede a escavações sucessivas - e cada vez mais profundas - de suas lembranças.

O investimento na subjetividade em favor da constituição de sujeitos leitores-escritores da própria história tem, pois, no gênero lírico importante aliado estético, de modo que a escritura das internas e sua relação com o suporte livro serão consideradas sob essa ótica. A produção e circulação do artefato literário nas dependências da instituição correcional, bem como nos espaços físicos e simbólicos intra e extramuros que com ela mantêm relação, repercutem nos processos de reposicionamento de indivíduos ante as dinâmicas de inclusão e exclusão nos/dos diversos sistemas culturais.

\section{Entre a contradição inicial e a mudança de paradigmas}

Impulsionado pelos distúrbios em prisões na França (assim como nos Estados Unidos), no início dos anos 1970, Michel Foucault passou a formular uma análise dos "métodos punitivos", não meramente como "consequências de regras de direito ou indicadores de estruturas sociais, mas como técnicas que têm sua especificidade no campo mais geral dos outros processos de poder" (Foucault, 2004, p. 26).

Desde então, novos paradigmas vêm sendo propostos ao estudo de diferentes sistemas culturais, notadamente os que arrogam, por princípio, o compromisso com a educação, reeducação, adaptação, conversão e cura de sujeitos considerados ameaça ao bom funcionamento das estruturas sociais. Assim, o deslocamento da punição dos domínios do corpo para os da alma - conforme pontuado pelo epistemólogo francês em sua história das prisões -, o castigo que, desde pelo menos as últimas décadas do 
século XVIII, passa a atuar "sobre uma realidade incorpórea", resulta em um regime de práticas punitivas que atinge, "profundamente, o coração, o intelecto, a vontade, as disposições" (Foucault, 2004, p. 21).

Não é, portanto, de se estranhar que o sistema prisional, ainda sob a vigência dessa regra geral de "não tocar mais o corpo, para atingir nele algo que não é o corpo propriamente" (Foucault, 2004, p.16), atue na supressão de direitos como parte de determinada economia interna de práticas. Tal regime, por um lado, justifica-se enquanto "medida de segurança" para a sociedade interna e externa às grades da instituição prisional; por outro, destina-se a sancionar a infração, controlar o indivíduo, modificar disposições criminosas, neutralizar sua periculosidade, entre outras tantas propriedades que atingem a alma do sujeito, ora julgando-a, ora impelindoa a participar de deliberado aprofundamento da pena.

Torna-se clara, pois, a intenção punitiva, ao se proibir a comunicação entre internas do presídio feminino ainda em funcionamento no estado brasileiro de Sergipe - o que ocorria até três anos atrás, em suas antigas instalações no bairro América, na capital Aracaju. A proibição de entrada de papéis, cadernos, folhas que pudessem servir de suporte para uma escrita individual, nas celas do presídio feminino, não se tratava unicamente de uma "medida de segurança" tampouco apenas o reflexo da alegada carência material na ordem da infraestrutura da instituição. Dialogava explicitamente com um modus operandi de lidar com criminosos, atingindo-lhes em suas vontades, impulsos e desejos humanos. Para um departamento de letras, localizado no município de São Cristóvão, a poucos quilômetros do presídio, esse fato emerge como justificativa de projeto de extensão. Provocava-nos a uma ação de pesquisa e consequente intervenção, desencadeadas pela constatação da supressão de direito constitucional cujo gozo, a nos so ver, poderia, ao contrário do que supunha o sistema, contribuir para o alcance dos objetivos de uma instituição penal.

Como contradição inicial, tinha-se o texto da Constituição Brasileira de 1988, em seu art. 5 , parágrafo IX, que inclui a livre expressão da atividade de comunicação como um dos termos que condiciona o inviolável direito à vida. Assegurada por artigo de lei específico, a liberdade de expressão corresponde, portanto, à necessidade inerente ao ser humano de estar em permanente estado de comunicação. 
No caso da população carcerária, esse direito parecia divergir de aspectos conceituais e ideológicos, o que se refletia na própria estrutura física dos espaços de confinamento. Além disso, o modo como as relações interpessoais eram ali reguladas reafirmava o isolamento, a incomunicabilidade, o anonimato, a despersonalização como elementos integrantes dos processos de sanção.

A repressão e controle que edificam um presídio como lócus da sanção, no estado de Sergipe, assim como em tantas outras instituições de mesma destinação, transformavam os atos comunicativos dos internos entre si e/ou entre aquela coletividade e o mundo extramuros, em atos de rebeldia, transgressão, inadaptabilidade, em outras palavras, insubordinação ao sistema - o que, paradoxalmente, concorria para o agravamento de sua condição de fora-da-lei. A despersonalização dos indivíduos em ambientes de confinamento e isolamento compulsório, vista como parte do processo de sanção do sujeito apenado, não concorre necessariamente para sua ressocialização.

Embora aparecesse como condição para a reinserção dos chamados transgressores ao convívio social, tal regime de práticas não parecia devolver à sociedade pessoas mais preparadas para lidar com os desafios de sua condição de ex-presidiários. $\mathrm{O}$ tempo passado nas casas de detenção é, em geral, ocioso e pouco produtivo no que concerne à reflexão sobre suas trajetórias de vida.

Novas conformações identitárias, surgidas com o afastamento do ambiente próprio e no convívio forçado com os outros detentos, reforçavam, no Presídio Feminino de Sergipe, a definição de Foucault sobre tais pessoas: "existências clarões". Seres apenas perceptíveis em situações específicas de confronto com a lei, sujeitos cuja "infâmia nada mais é do que uma variação da universal fama"; célebres por seus atos criminosos, pelo antagonismo crônico diante dos diversos poderes constituídos.

Contudo, enquanto práticas culturais inauguradoras de espaços de convívio, a leitura e a escrita apareciam, por vezes, clandestinamente, mediando relações interpessoais e reposicionando os sujeitos diante de dinâmicas de inclusão e exclusão. Ainda que atos comunicativos pudessem ser sistematicamente inibidos naqueles lugares (físicos e simbólicos), as atividades de leitura e escrita subsistiam como modo de resistência e imposição do componente humano, cultural, semiológico de que todos somos feitos. 


\section{Na genealogia do livro, uma necessária insubordinação}

A presença de profissional da área de segurança do estado de Sergipe entre o corpo discente da licenciatura em letras da UFS parecia corporificar determinado tipo de observação da realidade que o filósofo da modernidade qualificou em seu ensaio sobre $O$ narrador, nos seguintes termos:

objetos iluminados perdem os seus nomes: sombras e claridades formam sistemas e problemas particulares que não dependem de nenhuma ciência, que não aludem a nenhuma prática, mas que recebem toda sua existência e todo seu valor de certas afinidades singulares entre a alma, o olho e a mão de uma pessoa nascida para surpreender tais afinidades em si mesmo, e para as produzir (Benjamin, 1994, p. 220).

É da observação "quase mística" do artista que Benjamin aqui trata. Mas é do olhar interessado de um pesquisador em formação que se trata, quando se faz referência à dupla identidade de Rosângela Santos, aluna do curso de licenciatura em Português da UFS e guarda prisional do Prefem. Foi após a apresentação de seu trabalho intitulado "Gênero discursivo cartas" como requisito de conclusão da disciplina "Laboratório para o Ensino de Gêneros Textuais", do Departamento de Letras Vernáculas da UFS, que se começou projetar uma parceria entre as instituições. Parceria que se deu na forma de elaboração e introdução de ações de acompanhamento dos processos de produção e recepção de textos, no gênero cartas pessoais, entre internas do sistema prisional.

Na ocasião, ainda sob a interdição da entrada de materiais de escrita nas celas do presídio feminino, a produção de textos costumava se dar em suportes atípicos: tampas do vasilhame descartável das refeições (as chamadas "quentinhas") - o mais recorrente, mas também rótulos de cigarro, embalagens de sabonetes e outros tantos papéis de embrulho, rolinhos internos do papel higiênico, quaisquer materiais de empacotar que, porventura, caíssem nas mãos das internas.

A circulação apresentava certa regularidade, embora fosse assistemática do ponto de vista institucional. Em outras palavras, a interdição da entrada de papel e de outros materiais de escrita nas celas fazia com que o intercâmbio de cartas, assim produzidas de modo improvisado, com grafia minúscula para o total aproveitamento da superfície, por vezes muito pequena, se desse em uma espécie de 
clandestinidade de ações. A atividade envolvia boa parte das 189 internas (número atual) e excluía outro tanto.

O conteúdo das cartas variava entre: declarações de amor, de amizade, de diferentes formas de afeto entre as internas; expressões de desafeto, ódio e ressentimento; ameaças veladas ou explícitas; poemas autorais ou citações e paráfrases de versos conhecidos; relatos de acontecimentos internos às dependências dos pavilhões (divididos em alas, por sua vez segmentadas em celas); notícias de conversão, profissão de fé, fragmentos de discurso de autoajuda; notícias de fora do presídio (sabidas por meio da visitação semanal); entre o vasto temário de uma potencial conversação cotidiana, inviabilizada pela divisão espacial e retomada através dessa circulação clandestina de papéis escritos. O modo de distribuição variava entre o lançamento das tampas de quentinhas, como "discos voadores", por baixo das grades das celas, ou entrega mão a mão, das cartas e bilhetes com ou sem a anuência dos guardas prisionais.

\section{A insujeição como forma de ocupação discursiva}

A escrita de cartas em superfícies materiais atípicas, além de apontar para uma improvisação das condições para essa prática, confere um caráter emergencial ao ato de escrever. $\mathrm{O}$ sistema criado para sua distribuição no presídio feminino de Sergipe, naquela ocasião, envolveu, além de certa destreza das correspondentes em questão, capacidades de negociação com as agentes da lei. $\mathrm{O}$ exercício comunicativo, naqueles domínios e em tais condições, representa, por um lado, uma forma de resistência e de reposicionamento diante das dinâmicas de inclusão e de exclusão, conforme tipificadas na rotina do cárcere. A fala do indivíduo, codificada em linguagem verbal, alfabética, e textualizada em cartas, bilhetes, recados escritos, pequenas notas, insurge-se contra uma inapelável lista de interdições. Tais vetos estão assentados sobre um sólido padrão de regularidades, para o qual concorrem horários rígidos e coletivos para cada ação relacionada a uma necessidade básica à sobrevivência humana, segundo convenção e decisões externas àquele espaço. A inflexibilidade dessa rotina dificulta, por exemplo, a conversação em horários de refeição, bem como a privacidade e predileção nas relações interpessoais, as quais poderiam resultar em um gregarismo por afinidades. Outro padrão observado consiste na impossibilidade de comunicação intra e extramuros, fora das concessões oficiais, as quais são igualmente originárias de 
consensos externos. Tem-se, ainda, como certo o confinamento e suas gradações, baseadas na maior ou menor submissão ao conjunto de regras internas de conduta. A distribuição espacial dos sujeitos (em celas e pavilhões, por exemplo) se dá, comumente, por índices de periculosidade e/ou por uma avaliação arbitrária dos atos cometidos externamente, motivadores de sua condenação.

Tal controle sistemático, metódico, classificatório do cotidiano das internas remete à "mecânica do poder", conforme descrita por Foucault, "em sua forma capilar de existir, no ponto em que o poder encontra o nível dos indivíduos, atinge seus corpos, vem se inserir em seus gestos, suas atitudes, seu discursos, sua aprendizagem, sua vida quotidiana" (Foucault, 1979, p. 131). As mulheres apenadas, que cumpriam sua sentença em regime fechado e, por isso, tinham seus movimentos reduzidos, hipervigiados, passaram, então, através de uma escrita rebelde, porque desafiadora dessa estática compulsória, a gozar de uma forma incomum de mobilidade que, por força dos efeitos que acarreta, define-se como uma espécie de ocupação discursiva. Tal forma de alastramento do sujeito, por assim dizer, construído à base da leitura e da escrita, era também um modo de assumir o controle do próprio tempo-espaço, a despeito de regras impostas que atuam no sentido de sua negação.

A esse respeito, consideram-se os termos da Aula de Roland Barthes, que, em prolífera interlocução com Foucault, cita a "ubiquidade" como uma das propriedades do poder, em suas múltiplas formas. Assim, pela tomada da palavra, ao mesmo tempo "assertiva" (porque confere autoridade a seu portador) e "gregária" (porque alicia seguidores), ainda no dizer de Barthes, o sujeito se apropria também de certa forma de poder (Barthes, 1989, p. 13). É por meio dessa possibilidade de se espalhar; ocupar espaços interditados; continuar, para além do toque de recolher, na companhia do outro; fazer-se ouvir mesmo na ausência; promover, em meio a uma lógica isolacionista, grupos de interação verbal; fazer circular ideias, pensamentos, informações; textualizar o cotidiano, buscando imprimir nele outros sentidos - todas essas ações facultadas por e inerentes a processos de leitura-escrita - que se pode insurgir contra um regime limitante de enquadramento social e se empoderar pela inscrição nesse artificioso e autorregulamentado circuito comunicativo.

A razão dessa resistência e dessa ubiquidade é que o poder é o parasita de um organismo trans-social, ligado à história inteira do homem, e não somente à sua história política, histórica. Esse 
objeto em que se inscreve o poder, desde toda eternidade humana, é: a linguagem - ou, para ser mais preciso, sua expressão obrigatória: a língua. A linguagem é uma legislação, a língua é seu código. (Barthes, 1989, p. 13).

Há, por outro lado, mas decorrente desse mesmo processo de empoderamento, um movimento para dentro, desse sujeito que (se) escreve e que (se) lê, de modo transgressivo. Percebe-se, como efeito de tais licenciosos atos discursivos, uma autorreinvenção do sujeito. Ao buscar novas formas de atuar, lutando contra um sistema regulador da conduta que, efetivamente, inibe a interação verbal, o sujeito desenvolve aspectos identitários que permaneciam entorpecidos, ou menos evidentes, sob tal regime de práticas discursivas Torna-se, então, narrador da própria história, à maneira benjaminiana, porque tal narrativa é, de fato, significante de uma experiência. Em primeira pessoa, conta sobre si, e tal relato se sobrepõe, do ponto de vista da constituição do sujeito, àqueles constantes em seus processos penais, peças jurídicas, depoimentos transcritos, relatos de testemunhas ou sentenças judiciais.

A leitura-escrita de cartas, assim como a de poemas e diários, passa a contradizer, portanto, muitos dos estereótipos com os quais se edificavam, simbolicamente, o sistema prisional. Através de tais atos comunicativos, o sujeito redefine suas formas de ser e interage com espaços e tempos de um modo subjetivo. Reconstrói-se o percurso existencial através de opções narrativas que dotam de sentidos, de relações de causa e consequência, bem como de ordenação temporal e valorativa, o caos em que suas vidas se haviam transformado.

Por seu turno, a reconstrução da memória, viabilizada pelo tempo dedicado à leitura e à escrita, propicia novas leituras para episódios protagonizados por tais sujeitos. As vivências degradantes, revisitadas pela prática da "rememoração" (Benjamin, 1994), transformam-se em "experiência compartilhada" pelo uso da palavra, o que efetivamente concorre para a reinvenção da própria história e a possibilidade de projeção de novos horizontes e expectativas.

Sobre o já mencionado direito à comunicação, a bibliografia de referência utilizada no Presídio Feminino de Sergipe parece circunscrever as relações comunicativas ao "contato com o mundo exterior". A obra Administração penitenciária: uma abordagem dos direitos humanos, cujo subtítulo a define como Manual para servidores penitenciários, de Andrew Coyle (2002), em seu capítulo VIII, remete ao art. 12 da Declaração 
Universal dos Direitos Humanos: "Nenhuma pessoa está sujeita a interferência arbitrária em sua privacidade, família, lar ou correspondência" (grifo nosso). Relacionando diretamente o termo "correspondência" à "unidade grupal natural e fundamental da sociedade", a saber, à "família", o discurso faz parecer que a comunicação a que se refere o direito do interno está restrita, primeiro, ao mundo exterior e, logo a seguir, à família.

No mesmo capítulo, o manual arrola uma série de procedimentos institucionais que visam garantir o contato do interno com sua família, bem como a necessária disponibilização de aparelhos, veículos e materiais que possam agir como mediadores dessa correspondência: "Formas de contato que não visitas de familiares também são importantes. As pessoas presas devem poder enviar e receber correspondência tão livremente quanto possível e, quando viável, dar e receber telefonemas" (Coyle, 2002, p. 117).

Ainda nos domínios da comunicação, o texto discorre sobre a possibilidade de a população carcerária "manter-se atualizada sobre os acontecimentos da sociedade civil, tanto em suas comunidades de origem quanto no mundo em geral". Assim, aparelhos como televisão e rádio, além da leitura de impressos (livros, jornais e revistas) devem ser disponibilizados aos internos como "forma de se reduzir a anormalidade da experiência na prisão e também de assegurar que a pessoa presa não se torne completamente desvinculada da comunidade para onde ela voltará quando for solta" (Coyle, 2002, p. 117).

Embora muito se pudesse problematizar na leitura do manual, principalmente no que concerne à pesquisa de Foucault sobre espaços de confinamento e sua terapêutica específica para a "anormalidade" dos sujeitos (loucos, criminosos, inadaptados em geral), o que interessa, nesse caso, é a circunscrição do sentido de "correspondência' à relação intra e extramuros.

O novo na experiência de escrita de cartas em tampas de "quentinhas" está, justamente, no fato de os textos serem endereçados a outras internas ou a servidores(as) do sistema prisional que atuam dentro dos espaços compartilhados da instituição. Assim, ainda que fosse facultado às internas o direito a manterem contato com suas famílias e advogados, ou a terem notícias do mundo externo, era do mundo interno que elas queriam, efetivamente, dar e receber notícias. Era com pessoas daquela comunidade que elas almejavam se comunicar. Daí o sistema de 
escrita, envio e distribuição de cartas aparecer como prática fora do previsto pelos códigos de conduta, mesmo os que mais correspondessem aos, assim qualificados, direitos humanos.

As cartas escritas - a despeito de uma proibição, declarada ou engendrada pela interdição de acesso aos materiais de escrita tornaram-se, assim, ancestrais do gênero lírico de expressão, concretizado anos mais tarde pela publicação do primeiro livro de memórias, poemas e relatos de internas no sistema prisional em Sergipe.

\section{O formato livro: materialidade e substância}

Não por acaso, o grosso volume de 210 páginas, impresso em papel couché brilho, traz como primeiro texto - após foto de abertura, créditos, apresentação, prefácio, epígrafe e outros textos circundantes - a carta da interna Ildete Gomes Brasil endereçada a seu "Querido amigo Araripe". ${ }^{2}$

O livro, imponente na aparência, devido à qualidade da edição assinada pelo Ministério Público de Sergipe e pelas 80 fotografias em preto e branco, ampliadas e trabalhadas por profissional da área, traz em seu conteúdo verbal relatos autênticos e, de certo modo, simplistas das internas. Tal juízo não se deve a uma análise estética da produção nem de seu mérito literário, mas ao modo superficial com que os temas são tratados. O raciocínio binário de que se servem para julgar os episódios de que participam ou participaram - e que seus textos reconstroem - divide todas as suas vivências em dimensões como $\mathrm{bem} / \mathrm{mal}$, certo/errado, deus/diabo, entre outras.

Assim se apresenta a carta de Ildete, que, em 40 linhas (na edição impressa), divide sua trajetória de vida em três tópicos: passado, presente e futuro. O tom confessional e memorialístico do texto dá conta de uma história de más escolhas e arrependimentos. O tópico passado, muito mais extenso na redação que o do presente e o do futuro (seis parágrafos para o primeiro contra um para o segundo e um para o terceiro), apresenta uma sucessão de episódios rememorados segundo uma ótica moralista conservadora, com adjetivação profusa, muitas referências a Deus (na presença e ausência do reconhecimento dessa autoridade em momentos decisivos de sua vida), à família (iniciada com a alusão ao fato de ser

\footnotetext{
${ }^{2}$ Referência a Araripe Coutinho (1968-2014), poeta sergipano, integrante do coletivo de artistas responsável pelo Projeto Penarte.
} 
"filha única de pais separados") e aos relacionamentos amorosos determinantes de seu envolvimento com o narcotráfico.

A carta, ao contrário da suposta necessidade de correspondência com a família, com os sujeitos do mundo exterior à instituição, conforme prescrição do manual de administração penitenciária, é endereçada a alguém de dentro do sistema. Ou, pelo menos, constituinte de seu regime de práticas socioeducativas - o integrante do projeto Penarte. O texto dá conta de suas idas e vindas pelo mapa do Brasil, afirmando ter passado, ao todo, por presídios de três estados - São Paulo, Goiás e Sergipe. Seu périplo inclui momentos de caída, conversão, recaída, reconversão, enquanto seus três filhos cresciam, formavam-se e seguiam suas vidas, acolhidos por outros membros de sua família.

A detecção de tumores em seu corpo, o mandado de prisão por um novo envolvimento com venda ilegal de drogas e, por fim, a entrada do projeto Penarte no Presídio Feminino de Sergipe finalizam o relato difuso e entrecortado da carta de Ildete. Ao passo que ilustra os modos de apropriação da dicção lírica por alguém que necessita co-responder(-se) assim como as demais internas que participam do projeto livro -, Ildete necessita, pela escrita, ordenar os fatos de "uma vida que lhe custa viver", à maneira do contador de histórias descrito por Vargas Llosa.

Como para as sociedades, para o indivíduo também (o contar histórias) é uma atividade primordial, uma necessidade da existência, uma maneira de suportar a vida. Por que o homem necessita de contar e contar-se histórias? Talvez porque [...] dessa forma lute contra a morte e os fracassos, adquira uma certa ilusão de permanência e desagravo: é uma maneira de recuperar, dentro de um sistema que a memória estrutura com a ajuda da fantasia, esse passado que quando era experiência vivida tinha a aparência do caos (Vargas Llosa, 1982, p. 47).

A oficina de textos, responsável pela orientação da escrita, parece ter encaminhado os quase 100 relatos a começarem por um primeiro parágrafo de apresentação, quando as autoras se apresentam, com nome, idade e o crime pelo qual cumprem sentença. Daí em diante, por mais que o caráter subjetivo dos textos encaminhe a abordagem de suas histórias de vida para um tratamento diferenciado de episódios e fatos relacionados a seu ingresso no mundo do crime e a sua condenação, alguns temas são tão recorrentes que a impressão de já ter lido todos os textos, depois de se ter lido os três primeiros, é inevitável. 
As mulheres que, no dizer de Hall (Hall, 1997, p.25), realizam uma "narrativa de si", configuram-se, no decurso, como: filhas de alguém, esposas e namoradas de alguém, mães de alguém. Esse personagem coadjuvante (o alguém) que se edifica na correlação com a enunciadora de tais memórias divide igualmente com ela a responsabilidade (ou o preço pago) por seu atual estado de encarceramento. Todo o universo é, portanto, à maneira lírica, configurado a partir de sua relação com um eu que se revela e se desvela.

Ademais, as imagens que saltam de sua prosa rebuscada, de seu relato confessional ou dos ensaios líricos não se apresentam absolutamente libertas de um juízo. Fica clara a parcialidade no reconto das histórias na forma literária. Observa-se, ao longo das 200 páginas, certo apelo ao arbítrio favorável do leitor. Pleiteia-se, junto ao público, certa empatia ou identificação com o ser construído pelo dizer lírico.

A seleção dos episódios dignos do relato e da conformação poética é, igualmente, fruto de uma subjetivação do passado. Personagens, cenários, situações e épocas são escolhidas a dedo, de forma a endossar uma versão (ou subversão) do passado que se quer divulgar e em que se quer, efetivamente, acreditar. Atitudes que, certamente, concorrem para processos de ressocialização, uma vez que - para internos como para externos a instituições penais - a imagem de um passado justificado possibilita um presente tolerável e a projeção de um futuro dignificante: “Nunca podemos recuperar totalmente o que foi esquecido. E talvez seja bom assim. O choque do resgate do passado seria tão destrutivo que, no exato momento, forçosamente deixaríamos de compreender nossa saudade" (Benjamin, 1994, p. 105).

\section{Referências}

BARTHES, Roland (1989). Aula. São Paulo: Cultrix.

BENJAMIN, Walter (1994). O narrador: considerações sobre a obra de Nikolai Leskov. In: BENJAMIN, Walter. Magia e técnica, arte e política: ensaios sobre literatura e história da cultura. Tradução de Sergio Paulo Rouanet. Prefácio de Jeanne Marie Gagnebin. São Paulo: Brasiliense. (Obras escolhidas, v. I)

BENJAMIN, Walter (1997). Imagens do pensamento. In: BENJAMIN, Walter. Rua de mão única. Tradução de Rubens Rodrigues Torres Filho e José Carlos Martins Barbosa. São Paulo: Brasiliense. (Obras escolhidas, v. II) 
COYLE, Andrew (2002). Administração penitenciária: uma abordagem dos direitos humanos - Manual para servidores penitenciários. Londres: International Centre for Prison Studies.

FOUCAULT, Michel (1979). Microfísica do poder. Rio de Janeiro: Graal.

FOUCAULT, Michel (2004). Vigiar e punir: nascimento da prisão. Tradução de Raquel Ramalhete. 29. ed. Petrópolis: Vozes.

HALL, Stuart (1997). A identidade cultural na pós-modernidade. Tradução de Tomaz Tadeu da Silva. São Paulo: DP\&A.

SERGIPE. Ministério Público. Secretaria de Justiça do Estado de Sergipe. Outras vozes: poemas e relatos das presidiárias. Aracaju, 2012.

VARGAS LLOSA, Mario de (1982). A senhorita de Tácna. Rio de Janeiro: Francisco Alves.

Recebido em outubro de 2015.

Aprovado em março de 2016.

\section{resumo/abstract/resumen}

\section{Subversões do lírico no contexto prisional feminino de Sergipe}

Maria Aparecida Silva Ribeiro

O texto analisa a escritura de internas do sistema prisional sergipano, fomentada em intervenção cultural de coletivo de artistas locais, durante o ano de 2012, quando o total da população carcerária contava 239 mulheres. O formato livro dado, então, à síntese de registros autorais das presidiárias configura-se em corpus privilegiado na investigação sobre regimes de práticas discursivas (Foucault), tanto quanto no interesse pelos modos de apropriação do gênero lírico, enquanto dicção.

Palavras-chave: leitura, escrita, sistema prisional.

\section{Subversions of the lyrical in the context of the women's prison in Sergipe}

Maria Aparecida Silva Ribeiro

The text analyzes the writing of female inmates in the state prison system of Sergipe, created as a cultural intervention by the local collective of artists known as Penarte in 2012, when the total prison population totalled 239 women. The book format then given to the authorial narratives of prisoners configures a privileged corpus for 
research about the configuration of discursive practices (Foucault), as well as in the modes of appropriation of the lyrical genre in regards to its diction.

Keywords: reading, writing, prison system.

\section{Sub-versiones del género lírico en el contexto del cárcel de mujeres de Sergipe, Brasil}

\section{Maria Aparecida Silva Ribeiro}

El texto analiza la escritura producida por internas del sistema penitenciario de Sergipe, Brasil, promovida durante el año 2012 bajo la guía de un grupo de artistas locales, cuando la población carcelaria contaba con 239 mujeres. El formato de libro dado a la síntesis de los registros autoriales de las presidiarias se configura como un corpus privilegiado en la investigación sobre la práctica de los regímenes discursivos (Foucault), así como también sobre el interés por los modos de apropiación del género lírico en cuanto dicción.

Palabras clave: lectura, escritura, sistema penitenciario. 